\title{
Characterization and discrimination of phenolic compounds using Fourier transform Raman spectroscopy and chemometric tools
}

\author{
Darly R. Pompeu ${ }^{(1,2)}$, Yvan Larondelle ${ }^{(2)}$, Hervé Rogez ${ }^{(3)}$, Ouissam Abbas ${ }^{(4)}$, \\ Juan Antonio Fernández Pierna ${ }^{(4)}$, Vincent Baeten ${ }^{(4)}$ \\ (1) Universidade do Estado do Pará. Centre of Natural Science and Technology. Department of Food Technology. Trav. Éneas \\ Pinheiro 2626. BR-66.095-100 Belém-PA (Brazil). \\ (2) Université catholique de Louvain. Institut des Sciences de la Vie. Croix du Sud, 2/8. BE-1348 Louvain-la-Neuve \\ (Belgium). \\ (3) Universidade Federal do Pará \& Centre for Agro-food Valorisation of Amazonian Bioactive Compounds (CVACBA). \\ Faculty of Food Engineering. Av. da Ciência, km 01. BR-66.095-780 Belém-PA (Brazil). \\ (4) Walloon Agricultural Research Centre (CRA-W). Valorisation of Agricultural Products Department. Chaussée de Namur, \\ 24.BE-5030 Gembloux (Belgium).E-mail: o.abbas@cra.wallonie.be, v.baeten@cra.wallonie.be
}

Received 9 May 2017, accepted 17 October 2017, available online 24 October 2017.

This article is distributed under the terms and conditions of the CC-BY License (http://creativecommons.org/licenses/by/4.0)

Description of the subject. Phenolic compounds (PCs) are the most abundant secondary metabolites in plants. This work was part of a study that sought to develop rapid screening FT-Raman methods for identifying and quantifying classes and/or types of PCs in the dry extracts of plant products.

Objectives. Fourier transform Raman spectroscopy (FT-Raman) coupled with chemometric tools was used to characterize and discriminate four families of phenolic compounds: two important classes of phenolic acids, hydroxybenzoic and hydroxycinnamic acids, as well as their derivatives and flavonoids.

Method. For this study, 25 standards of phenolic compounds were used (47 standards in total, taking account of the different brands). Repeatability and reproducibility studies were conducted to verify the Raman assignments of gallic acid. Raman characterization with the most significant spectral bands of phenolic compounds was done using spectra ranging from 1,800 to $50 \mathrm{~cm}^{-1}$. A Fisher test was applied to pre-processed Raman spectra (SNV) and 20 Raman scattering signals were used to differentiate each class of phenolic compounds.

Results. Hydroxybenzoic acids, hydroxycinnamic acids, their derivatives and flavonoids have been characterized by Raman spectroscopy; bands have been identified and differentiated within and between groups.

Conclusions. The scattering intensities located around 1,600-1,699, 1,300-1,400 and below $200 \mathrm{~cm}^{-1}$ were responsible for differentiating $100 \%$ of phenolic compound families, classes and subclasses.

Keywords. Spectroscopy, phenolic compounds, hydroxybenzoic acids, hydroxycinnamic acids, flavonoids.

Caractérisation et discrimination des composés phénoliques à l'aide de la spectroscopie Raman à transformée de Fourier et des outils chimiométriques

Description du sujet. Les composés phénoliques (CP) sont les métabolites secondaires les plus abondants dans les plantes. Ce travail fait partie d'une étude visant à développer des méthodes rapides de criblage FT-Raman pour identifier et quantifier les classes et/ou types de CPs dans les extraits secs ou les végétaux.

Objectifs. La spectroscopie Raman à transformée de Fourier (FT-Raman) couplée à des outils chimiométriques a été utilisée pour caractériser et distinguer quatre familles de composés phénoliques : deux importantes classes d'acides phénoliques, à savoir des acides hydroxybenzoïques et hydroxycinnamiques, ainsi que leurs dérivés et des flavonoïdes.

Méthode. Pour cette étude, 25 standards de composés phénoliques ont été utilisés (47 standards au total, en tenant compte des différentes marques). Des études de répétabilité et de reproductibilité ont été effectuées pour vérifier les affectations Raman de l'acide gallique. La caractérisation Raman a été réalisée sur base des bandes spectrales les plus significatives dans la région allant de 1800 à $50 \mathrm{~cm}^{-1}$. Un test Fisher a été appliqué à des spectres Raman pré-traités (SNV) et 20 des signaux Raman ont été utilisés pour distinguer chaque classe de composés phénoliques. 
Résultats. Les acides hydroxybenzoïques, les acides hydroxycinnamiques, leurs dérivés et des flavonoïdes ont été caractérisés par spectroscopie Raman ; les bandes ont été identifiées et différenciées au sein mais aussi entre les groupes.

Conclusions. Les intensités Raman situées autour de 1600-1699, de 1300-1 400 et inférieures à $200 \mathrm{~cm}^{-1}$ sont responsables de la différenciation de $100 \%$ des familles de composés phénoliques, des classes et sous-classes.

Mots-clés. Spectroscopie, composés phénoliques, acides hydroxybenzoïques, acides hydroxycinnamiques, flavonoïdes.

\section{INTRODUCTION}

Phenolic compounds (PCs) are the most abundant secondary metabolites in plants. They comprise a wide variety of molecules that have a phenolic structure consisting of a hydroxyl group (-OH) bonded directly to an aromatic hydrocarbon group (Robards et al., 1999; Ignat et al., 2011). Between May 2005 and May 2015, PCs have been cited more than 29,985 times in the literature (scopus.com, title, abstract or keywords, accessed 21 May 2015), illustrating their importance in the scientific world. Despite this importance, there has been limited work on correctly identifying and quantifying them. The current techniques used to determine PCs need trained personnel, are time consuming, and cannot be used for real-time measurements because their application to raw material control remains very limited (Baeten et al., 2015). Rapid, non-destructive and adaptable on-line techniques are needed for the fast characterization of bioactive compounds, especially PCs.

Raman spectroscopy is a branch of vibrational spectroscopy based on shifts in the wavenumber or frequency of an incident exciting monochromatic radiation. The shift results from the inelastic scattering of interaction between the photons and the sample. Raman spectroscopy is usually measured in the 3,600$200 \mathrm{~cm}^{-1}$ range. This region corresponds to Raman Stokes scattering bands. This spectroscopic technique is used in chemistry to identify (Schrader et al., 1999; Baranska et al., 2004; Baranska et al., 2006) and characterize substances (Schulz et al., 2005; PaivaMartins et al., 2011; Zuk et al., 2011) and compounds (Fiuza et al., 2004; Teslova et al., 2007; Corredor et al., 2009; Świsłocka et al., 2012; Machado et al., 2013; Mishra et al., 2013) and to study molecular and crystalline symmetries and identify crystalline polymorphism of compounds (Numata \& Tanaka, 2011). The most commonly used Raman spectroscopies are based on two technologies, dispersive Raman and Fourier transform (FT) Raman. Each technology has its advantages and is suited to specific types of analysis. FT-Raman avoids most of the fluorescence perturbation and provides spectra with high frequency precision.

Raman spectroscopy exhibits well-resolved bands of fundamental vibrational transitions and provides a useful amount of information on the molecular structure of compounds. In the case of PCs, spectral features such as the presence or absence of scattering bands, as well as band scattering positions, have been reported in the literature. Billes et al. (2007) investigated the assignment of the Raman spectra of gallic acid in its crystalline form and the spectral changes due to the presence of water in the structure. Calheiros et al. (2008) studied the influence of the ester alkyl chain (methyl, ethyl, propyl, isopropyl, butyl, octyl and dodecyl groups) on Raman spectral features of caffeic, ferulic and gallic acids. Świsłocka et al. (2013) reported spectral features of three hydroxybenzoic acids (4-hydroxybenzoic, vanillic and syringic acids) and two benzoic derivative (benzoic and 3-methoxybenzoic acids) standards. Eravuchira et al. (2012) investigated the Raman spectra of derivatives of cinnamic acids (3-caffeoylquinic, 4-caffeoylquinic, 5-caffeoylquinic, 3,4-di-o-caffeoylquinic, 3,5-di-o-caffeoylquinic, 4,5-di-o-caffeoylquinic and 3-feruloylquinic acids). In all these studies, vibrational bands were assigned and pointed to characterize these PCs. To date, however, no systematic approach has been developed to differentiate the PCs.

In this study, FT-Raman spectroscopy was used to characterize 25 standards of PCs: six hydroxybenzoic acids (gentisic, protocatechuic, gallic, 4-hydroxybenzoic, vanillic, syringic acids) and four hydroxycinnamic acids (2-hydroxycinnamic, caffeic, ferulic, and sinapic acids), as well as four of their derivatives (catechol, chlorogenic acid, resveratrol and tannic acid) and 11 flavonoids (bavachinin, catechin, daidzein, epicatechin, epicatechin gallate, epigallocatechin, epigallocatechin gallate, genistein, luteolin, quercetin dihydrate and rutin). Various chemometric tools applied to the characteristic Raman spectra were used to exhibit key bands, allowing differentiation between families, classes and subclasses of PCs. This work was part of a study that sought to develop rapid screening FT-Raman methods for identifying and quantifying classes and/or types of PCs in the dry extracts of plant products.

\section{MATERIALS AND METHODS}

\subsection{Chemicals}

The chemical standards of the hydroxybenzoic acids, hydroxycinnamic acids, their derivatives and the flavonoids were purchased from Sigma-Aldrich (Steinheim, Germany), Extrasynthèse (Genay, France) 
and VWR (Darmstadt, Germany) (Table 1). In total, 47 standards (HPLC grade with purity $>95 \%$ ) were used in the study. The samples were stored at $-20{ }^{\circ} \mathrm{C}$ and room-conditioned $1 \mathrm{~h}$ before the start of the analysis.

\subsection{Optimization of measurement conditions, repeatability and reproducibility}

Gallic acid was used to optimize the measurement conditions of PCs using FT-Raman:

- two weights ( 3 and $5 \mathrm{mg}$ ) of gallic acid were manually placed and compacted in ten small aluminium ring cups;

- three laser power intensities were used $(100,200$ and $400 \mathrm{~mW}$ );

- FT-Raman scattering data were collected with a spectral resolution of $1 \mathrm{~cm}^{-1}$ by co-adding 32,64 , 128,256 and 512 scans.

Once the measurement parameters had been optimized, FT-Raman measurements were taken over 4 days in order to verify the repeatability and reproducibility of this technique for PC determination.

\subsection{Raman spectroscopy}

FT-Raman spectra were acquired on a Vertex 70-RAM II FT-Raman spectrometer obtained from Bruker (Bruker Optics, Ettlingen, Germany), equipped with an Nd:YAG laser (Yttrium Aluminium Garnet crystal doped with triply ionized Neodymium) with an output at $1,064 \mathrm{~nm}$ (or $9,398.5 \mathrm{~cm}^{-1}$ ) and a liquid-nitrogen cooled germanium detector.

The samples were manually placed and compacted in small aluminium ring cups with a hole that had an inner diameter of $2 \mathrm{~mm}$. Spectra were recorded from 50 to $3,599 \mathrm{~cm}^{-1}$. Each PC was independently and randomly measured in duplicate.

OPUS 6.0 Software (Etlingen, Germany) was used for the spectral data acquisition.

\subsection{Chemometric analysis}

Spectral data were smoothed using the Savitzky-Golay algorithm (using a 3 points window and a second order polynomial). Matlab 7.14 (The Mathworks, Natick, MA) was used to develop and apply an algorithm to identify wavenumbers where the Raman scattering intensity was at least $5 \%$ of the maximum Raman

Table 1. Phenolic compounds used in this study - Composés phénoliques utilisés dans cette étude.

\begin{tabular}{|c|c|c|}
\hline Class & Phenolic compound & Brands \\
\hline Hydroxybenzoic acids & $\begin{array}{l}\text { Gentisic acid } \\
\text { Protocatechuic acid } \\
\text { Gallic acid } \\
\text { 4-hydroxybenzoic acid } \\
\text { Vanillic acid } \\
\text { Syringic acid }\end{array}$ & $\begin{array}{l}\text { Extrasynthèse, Sigma-Aldrich, VWR } \\
\text { Extrasynthèse, Sigma-Aldrich, VWR } \\
\text { Extrasynthèse, Sigma-Aldrich, VWR } \\
\text { Extrasynthèse, Sigma-Aldrich } \\
\text { Extrasynthèse, Sigma-Aldrich, VWR } \\
\text { Extrasynthèse, Sigma-Aldrich, VWR }\end{array}$ \\
\hline Hydroxycinnamic acids & $\begin{array}{l}\text { 2-hydroxycinnamic acid } \\
\text { Caffeic acid } \\
\text { Ferulic acid } \\
\text { Sinapic acid }\end{array}$ & $\begin{array}{l}\text { Extrasynthèse, Sigma-Aldrich } \\
\text { Extrasynthèse, Sigma-Aldrich, VWR } \\
\text { Extrasynthèse, Sigma-Aldrich } \\
\text { Extrasynthèse, Sigma-Aldrich }\end{array}$ \\
\hline $\begin{array}{l}\text { Derivatives of hydroxybenzoic and } \\
\text { hydrocinnamic acids }\end{array}$ & $\begin{array}{l}\text { Chlorogenic acid } \\
\text { Ellagic acid } \\
\text { Resveratrol } \\
\text { Tannic acid } \\
\end{array}$ & $\begin{array}{l}\text { Extrasynthèse, Sigma-Aldrich, VWR } \\
\text { Extrasynthèse, Sigma-Aldrich } \\
\text { Extrasynthèse } \\
\text { Extrasynthèse, Sigma-Aldrich, VWR* }\end{array}$ \\
\hline Flavonoids & $\begin{array}{l}\text { Bavachinin } \\
\text { Catechin } \\
\text { Daidzein } \\
\text { Epicatechin } \\
\text { Epicatechin gallate } \\
\text { Epigallocatechin } \\
\text { Epigallocatechin gallate } \\
\text { Genistein } \\
\text { Luteolin } \\
\text { Quercetin dehydrated } \\
\text { Rutin }\end{array}$ & $\begin{array}{l}\text { Extrasynthèse } \\
\text { Extrasynthèse } \\
\text { Extrasynthèse } \\
\text { Extrasynthèse } \\
\text { Extrasynthèse } \\
\text { Extrasynthèse } \\
\text { Extrasynthèse } \\
\text { Extrasynthèse } \\
\text { Extrasynthèse } \\
\text { Extrasynthèse } \\
\text { Extrasynthèse }\end{array}$ \\
\hline
\end{tabular}

*: two different tannic acids purchased from VWR were used in this study - deux acides tanniques différents achetés chez VWR ont été utilisés dans cette étude. 
scattering intensity. To confirm these Raman bands, second derivative pre-processing was performed using the Savitzky-Golay transformation (second order polynomial; 3 points at right and left).

Separations between families, classes and subclasses of PC were made using Raman data with standard normal variate (SNV) pre-processing. Unscrambler® X 10.3 Software, from CAMO (Computer Aided Modelling, Trondheim, Norway), was used to do classifications.

\section{RESULTS AND DISCUSSION}

\subsection{Optimization of measurement conditions, repeatability and reproducibility}

The most commonly used method to quantify total PC content is the colorimetric method using the FolinCiocalteu reagent. With this method, calibration curves are usually built using gallic acid for its high stability (Volf et al., 2014), although other chemical standards can be employed, e.g. caffeic, chlorogenic and tannic acids. Gallic acid was therefore chosen for the first step of the study.

The measurement conditions were tested:

- amounts of gallic acid in the aluminium ring cup (3 or $5 \mathrm{mg}$ );

- laser power intensity (100, 200 and $400 \mathrm{~mW})$;

- number of scans collected $(32,64,128,256$ or 512).

As expected, the Raman scattering peaks were the same, irrespective of the measurement conditions (data not shown). With regard to sample quantity, $5 \mathrm{mg}$ were selected as being easier to compact inside the small ring than $3 \mathrm{mg}$. A laser power intensity of $100 \mathrm{~mW}$ gave low Raman scattering intensities, whereas $400 \mathrm{~mW}$ could have caused fluorescence damage (Baeten et al., 2001); the intensity was therefore set at $200 \mathrm{~mW}$. The number of scans chosen was 128; below this number (32 and 64 scans) the Raman spectra quality was not good enough to give a clear determination, and working with more than 128 would have required a long measurement time.

Once the FT-Raman conditions had been optimized, precision tests were done. The precision with which the FT-Raman technique is able to characterize PCs was evaluated in terms of repeatability and reproducibility. Repeatability is measurement results under conditions where independent measurement results are obtained with the same method on the identical test items in the same laboratory by the same operator using the same equipment within short intervals of time (ISO 5725, 1994). Reproducibility can be defined as the closeness of agreement between independent results obtained with the same method on identical material but under different conditions. These precision parameters were evaluated in terms of Raman scattering data $\left(\mathrm{cm}^{-1}\right)$.

In order to calculate these factors, 10 spectra (each one the mean of 128 scans) of gallic acid were collected over 4 days. Slight differences in Raman intensity and Raman scattering signal shifts were observed in six spectral ranges: 1,260-1,250, 1,100-1,080, 960$950,710-685,285-275$ and $140-120 \mathrm{~cm}^{-1}$. A second derivative pre-processing on spectral data, however, demonstrated that there were no spectral differences in the Raman scattering data. Figure 1 presents the original FT-Raman spectra (a) and second derivative FT-Raman spectra (b) obtained from gallic acid.

All interpretations of spectra in our study were based in Socrates (1997).

\subsection{Raman characterization of hydroxybenzoic acids}

Figure 2 shows the FT-Raman spectra of six hydroxybenzoic acids from different companies in the region of $50-1,800 \mathrm{~cm}^{-1}$. The most important Raman scattering signals observed are summarized in table $\mathbf{2}$, indicating that these PCs present important spectral information in the region studied.

The FT-Raman spectra of hydroxybenzoic acids showed two series of intense spectral bands: the most intense was below $200 \mathrm{~cm}^{-1}$ and the second most intense was between 1,715 and $1,590 \mathrm{~cm}^{-1}$. The first one was due to skeletal vibration; this region is also useful for describing lattice vibrations, the main manifestation of the intermolecular forces in crystals. The second one was due to aryl carboxylic acid $\mathrm{C}=\mathrm{O}$ stretching vibrations $\left(1,715-1,680 \mathrm{~cm}^{-1}\right)$ and $\mathrm{C}=\mathrm{C}$ stretching vibrations from the aromatic ring $(1,625$ $\left.1,590 \mathrm{~cm}^{-1}\right)$. Some spectral signals were also observed around 1,410-1,310 $\mathrm{cm}^{-1}$, associated mainly with $\mathrm{O}-\mathrm{H}$ deformation and $\mathrm{C}-\mathrm{O}$ stretching combination vibrations of phenols. Aromatic $=\mathrm{C}-\mathrm{H}$ in-plane and out-of-plane deformation vibrations were visible in the 1,290$1,000 \mathrm{~cm}^{-1}$ and $965-680 \mathrm{~cm}^{-1}$ regions, respectively. The region between 650 and $415 \mathrm{~cm}^{-1}$ is more characteristic of aromatic ring vibrations.

\subsection{Raman characterization of hydroxycinnamic acids}

Figure 3 shows the FT-Raman spectra of four hydroxycinnamic acids from different brands in the region of $50-1,800 \mathrm{~cm}^{-1}$. The most important Raman scattering signals observed are summarized in table 3 .

The hydroxycinnamic acids studied presented a spectral region below $200 \mathrm{~cm}^{-1}$ less intense than the hydroxybenzoic acids. The most intense spectral bands of hydroxycinnamic acids were in the 1,1501,360 and 1,650-1,590 $\mathrm{cm}^{-1}$ regions. Compared with 

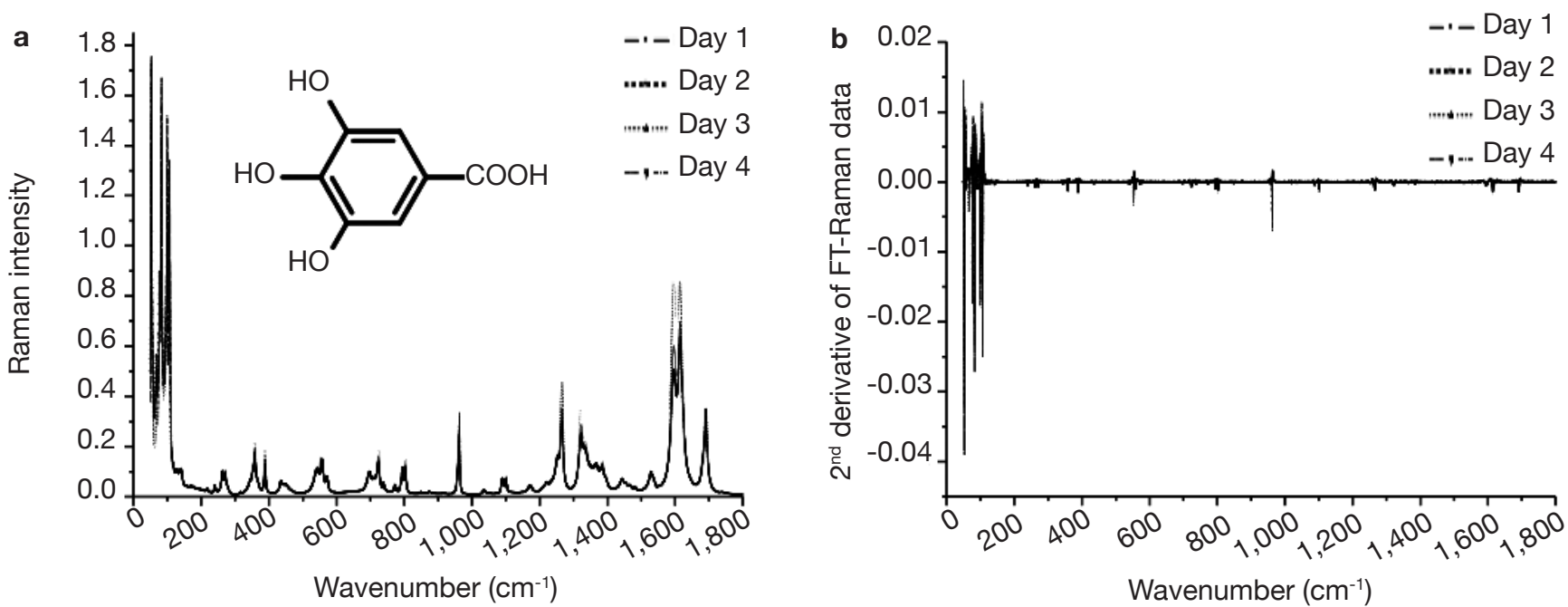

Figure 1. Chemical structures and FT-Raman spectral data of gallic acid. Normal Raman (a) and second derivative FT-Raman data (b) of gallic acid. These figures express average of 10 samples of 3,4,5-trihydroxybenzoic acid measured independently during four days - Structure chimique et données spectrales FT-Raman d'acide gallique. Données Raman brutes (a) et de dérivée seconde (b) d'acide gallique. Ces chiffres expriment la moyenne de 10 spectres d'acide 3,4,5-trihydroxybenzoïque mesurés indépendamment pendant quatre jours.

hydroxybenzoic acids, hydroxycinnamic acids have an alkene group between the carboxylic function and the aromatic ring, which results in $\alpha, \beta$-unsaturated carboxylic acid theoretically absorbing between 1,715 and $1,680 \mathrm{~cm}^{-1}$. Surprisingly, this band was not visible in our study. The alkene group $\mathrm{C}=\mathrm{C}$ presents bands between 1,640 and $1,610 \mathrm{~cm}^{-1}$ due to its conjugation with aryl, but it is also conjugated with $\mathrm{C}=\mathrm{O}$, leading to vibration bands between 1,660 and 1,580 $\mathrm{cm}^{-1}$.

\subsection{Raman characterization of derivatives of hydroxybenzoic and hydroxycinnamic acids}

Figure 4 presents the FT-Raman spectra of ellagic acid, chlorogenic acid, resveratrol and tannic acid from different brands in the $50-1,800 \mathrm{~cm}^{-1}$ region. Table 4 shows the pointed bands.

Chlorogenic acid and resveratrol presented the two highest peaks in the $1,640-1,600 \mathrm{~cm}^{-1}$ spectral region. They can be differentiated by the presence of a small band around $1,690 \mathrm{~cm}^{-1}$ corresponding to $\mathrm{C}=\mathrm{O}$ stretching vibration of aryl and $\alpha, \beta$-unsaturated ester. For both PCs, the spectral region between 1,000 and $1,400 \mathrm{~cm}^{-1}$ was rich in Raman scattering signals. Resveratrol composed of two aromatic rings presented several better resolved and more intense bands in the $1,000-1,400 \mathrm{~cm}^{-1}$ region than chlorogenic acid. Tannic acid, which has the most complex structure of all the PCs studied, presented spectral bands that were the least resolved. Ellagic acid deserves some attention. It showed a strong shift as a function of the brand (source company). This shift was confirmed when a second derivative pre-treatment was applied. The most remarkable differences were at 1,554-1,532, 1,374-1,350, 1,305-1,290, 1,210-1,170, 1,065-1,050, $790-630,560-320$ and below $200 \mathrm{~cm}^{-1}$. It should be remembered that ellagic acid has a center of symmetry; it has a planar compact structure where molecules are interconnected. This might explain the resulting spectrum which was rich in well-resolved bands over the entire spectrum, in addition to bands below $200 \mathrm{~cm}^{-1}$ which were numerous and very intense.

\subsection{Raman characterization of flavonoids}

Flavonoids are molecules with a phenolic benzopyran structure and occur only in plants. They represent a family of PCs. They share a common nucleus consisting of two phenolic rings and an oxygenated heterocycle, and can be divided into classes according to the type of heterocycle involved. In this study, 11 flavonoids from 5 classes (flavanol, flavanone, flavone, flavonol, isoflavone) were investigated.

Figures 5a and $\mathbf{5 b}$ present the FT-Raman spectra of flavonoids in the $50-1,800 \mathrm{~cm}^{-1}$ region. Table 5 shows the pointed signals.

The most intense spectral region was observed below $200 \mathrm{~cm}^{-1}$ for almost all the flavonoids. The exceptions were luteolin and rutin. All the flavonoids showed a very important spectral region between 1,570 and $1,700 \mathrm{~cm}^{-1}$. Phenolic compounds without carbonyl function, however, e.g. the flavanols as catechin, epicatechin and epigallocatechin, had only one band around $1,600 \mathrm{~cm}^{-1}\left(1,633,1,617,1,627 \mathrm{~cm}^{-1}\right.$, respectively) corresponding to the stretching vibrations of aromatic $\mathrm{C}=\mathrm{C}$ groups. The rest of the PCs presented 
a

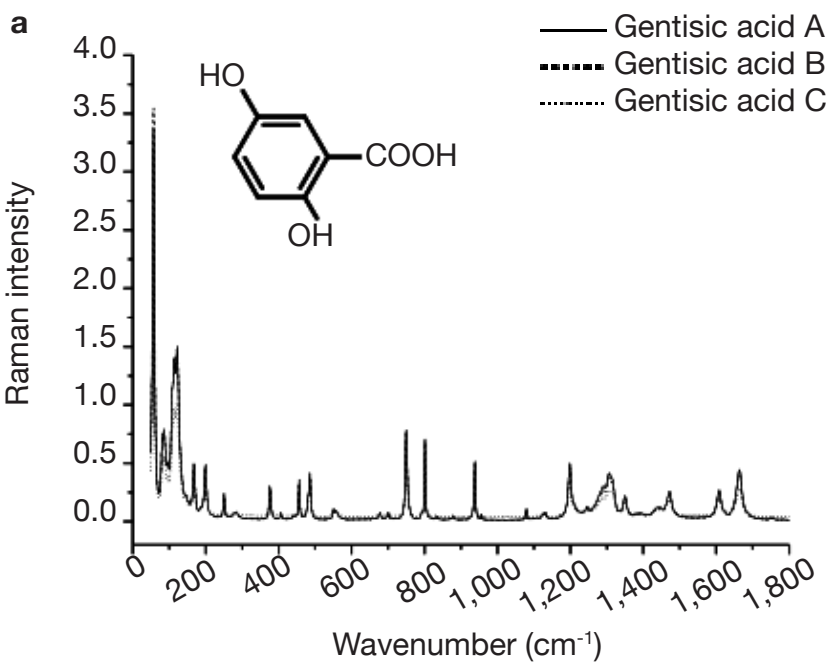

C
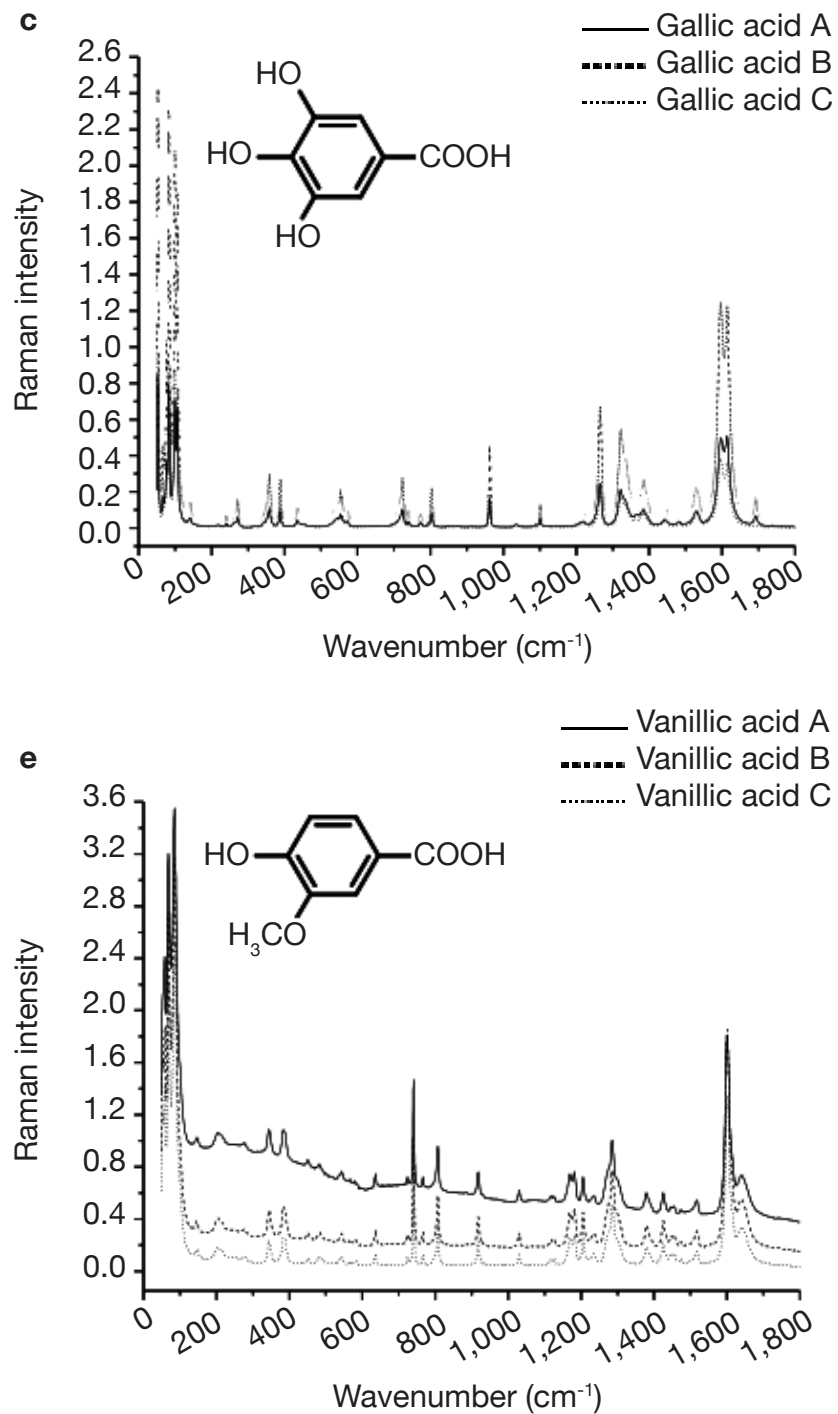
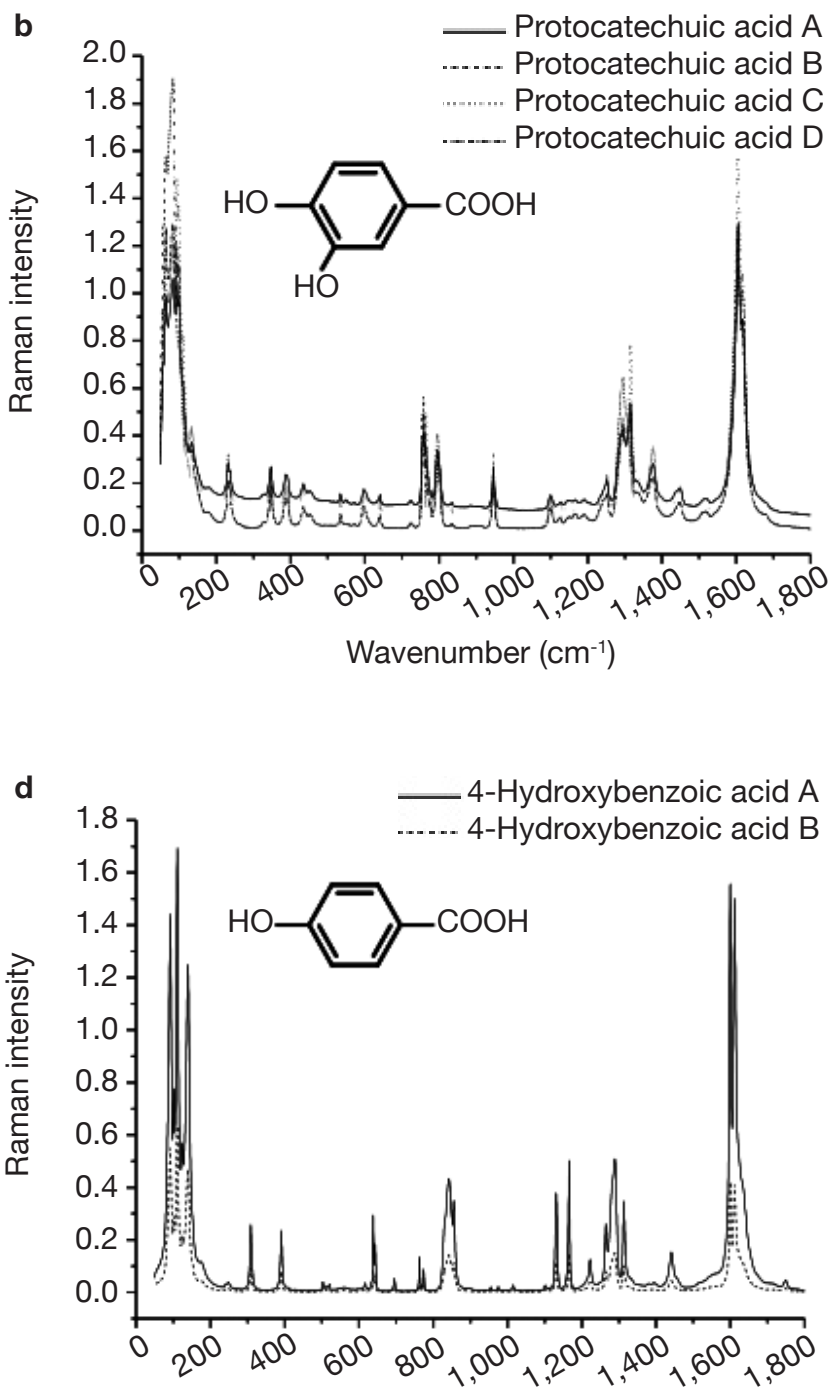

Wavenumber $\left(\mathrm{cm}^{-1}\right)$

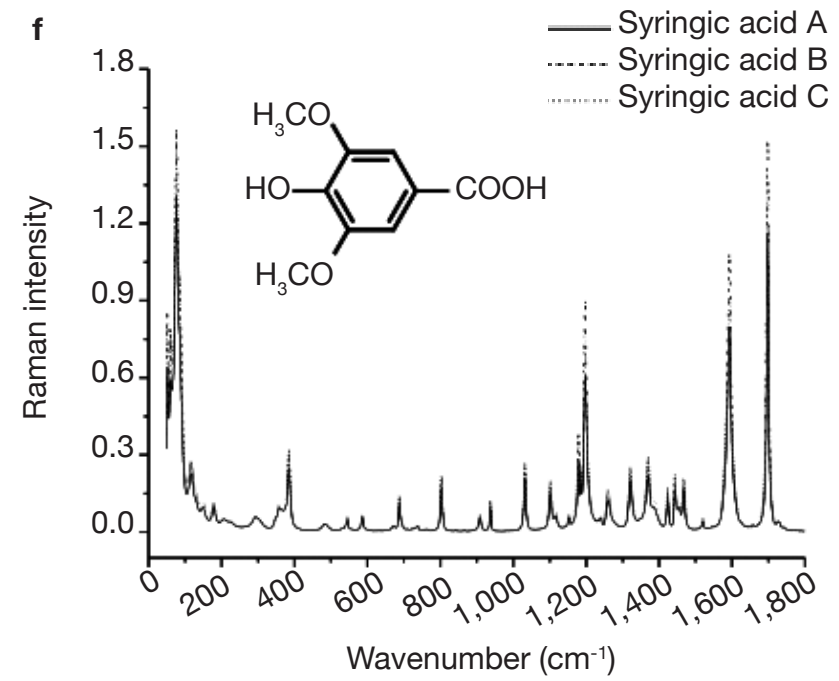

Figure 2. Raman spectra and chemical structures of gentisic (a), protocatechuic (b), gallic (c), 4-hydroxybenzoic (d), vanillic (e) and syringic (f) acids - Spectres Raman et structures chimiques des acides gentisique (a), protocatéchuique (b), gallique (c), 4-hydroxybenzö̈que $(\boldsymbol{d})$, vanillique $(\boldsymbol{e})$ et syringique $(\boldsymbol{f})$. 
Table 2. The most intense Raman scattering signals $\left(\mathrm{cm}^{-1}\right)$ of gentisic, protocatechuic, gallic, 4-hydroxybenzoic (4HB), vanillic and syringic acids - Les signaux Raman les plus intenses $\left(\mathrm{cm}^{-1}\right)$ des acides gentisique, protocatéchuique, gallique, 4-hydroxybenzö̈que (4HB), vanillique et syringique.

\begin{tabular}{|c|c|c|c|c|c|}
\hline \multicolumn{6}{|c|}{ Hydroxybenzoic acids } \\
\hline Gentisic & Protocatechuic & Gallic & $4 \mathrm{HB}$ & Vanillic & Syringic \\
\hline $1,663-1,664_{v w}$ & $1,617-1,618_{v s}$ & $1,691_{v w}$ & $1,612_{v s}$ & $1,602_{v s}$ & $1,697-1,698_{v s}$ \\
\hline $1,315_{v w}$ & $1,605_{v s}$ & $1,614_{s}$ & $1,600_{v s}$ & $1,598_{v s}$ & $1,593_{s}$ \\
\hline $1,306-1,307_{v w}$ & $1,315_{v s}$ & $1,596_{s}$ & $1,441_{v w}$ & $1,519-1,520_{v w}$ & $1,467-1,468_{v v}$ \\
\hline $1,290_{v w}$ & $1,295-1,296_{m}$ & $1,530_{v w}$ & $1,313_{w}$ & $1,425_{w}$ & $1,443_{v w}$ \\
\hline $1,198-1,199_{v w}$ & $1,251_{w}$ & $1,384-1,386_{v w}$ & $1,289_{w}$ & $1,378-1,379_{w}$ & $1,370_{w}$ \\
\hline $938_{v w}$ & $1,095_{s}$ & $1,365_{v w}$ & $1,265_{v w}$ & $1,284-1,285_{m}$ & $1,321_{w}$ \\
\hline $801_{w}$ & $946_{w}$ & $1,333_{v w}$ & $1,166_{w}$ & $1,205_{w}$ & $1,260_{v w}$ \\
\hline $750_{w}$ & $794-796_{m}$ & $1,322_{w}$ & $1,131_{w}$ & $1,182-1,183_{w}$ & $1,197_{s}$ \\
\hline $486_{v w}$ & $793-794_{m}$ & $1,264-1,266_{m}$ & $855_{w}$ & $1,167-1,168_{w}$ & $1,185_{w}$ \\
\hline $456_{v w}$ & $775-777_{w}$ & $963_{w}$ & $842_{w}$ & $916-918_{w}$ & $1,179_{w}$ \\
\hline $375_{v w}$ & $770_{w}$ & $803_{v w}$ & $763_{v w}$ & $807-808_{w}$ & $1,102_{v w}$ \\
\hline $199_{v w}$ & $758-759_{m}$ & $724_{v w}$ & $644_{v w}$ & $741_{s}$ & $1,032_{w}$ \\
\hline $168_{v w}$ & $755-754_{m}$ & $553_{v w}$ & $638_{v w}$ & $724_{v w}$ & $937_{v w}$ \\
\hline $147_{v w}$ & $534-535_{w}$ & $388_{v w}$ & $391_{v w}$ & $637_{v w}$ & $803_{v w}$ \\
\hline $122_{s}$ & $347-348_{w}$ & $359_{v w}$ & $308_{v w}$ & $383_{w}$ & $688_{v w}$ \\
\hline $114_{s}$ & $231-233_{m}$ & $106_{v s}$ & $139_{v s}$ & $343-344_{w}$ & $148-149_{v w}$ \\
\hline $96_{w}$ & $99-100_{v s}$ & $99_{v s}$ & $124_{m}$ & $86_{v s}$ & $116-117_{w}$ \\
\hline $86_{w}$ & $93-94_{v s}$ & $83_{v s}$ & $111_{v s}$ & $68_{v s}$ & $76_{v s}$ \\
\hline $80_{w}$ & $83-85_{v s}$ & $76_{s}$ & $101_{s}$ & $58-59_{v s}$ & $60-61_{s}$ \\
\hline $57_{v s}$ & $63-64_{v s}$ & $68_{w}$ & $92_{v s}$ & $52_{v s}$ & $52_{s}$ \\
\hline & & $52_{v s}$ & & & \\
\hline
\end{tabular}

Each compound from each brand was measured independently twice. These Raman scattering signals represent the average of these measures. The Raman scattering signals were codded with $v w$ (very weak: 5-10\%), $w$ (weak: 10-20\%), $m$ (medium: 20-30\%), s (strong: $30-40 \%$ ) and $v s$ (very strong: $>40 \%$ ) in function of their relative Raman intensities concerning the highest Raman intensity - Chaque composé de chaque marque a été analysé deux fois indépendamment. Ces signaux représentent la moyenne de ces mesures. Les signaux Raman ont été codés avec vw (très faible : 5-10\%), w (faible : 10-20\%), m (moyen : 20-30\%), s (fort: $30-40 \%$ ) et vs (très fort : > $40 \%$ ) en fonction de leurs intensités Raman relatives à l'intensité la plus élevée.

several bands in this region and had one band at a higher wavenumber that might have been linked to carbonyl groups of hydroxylated-4H-1-benzopyran-4-one of daidzein, genistein (isoflavones), quercetin hydrate, rutin (flavonols) or luteolin (flavone). In the case of epicatechin gallate and epigallocatechin gallate, the ketone function was related to the ester group, which could explain the highest recorded wavenumbers at 1,683 and $1,692 \mathrm{~cm}^{-1}$, respectively.

For the flavanone, only the PC bavachinin was available. In addition to all the bands associated with aromatic rings and hydroxyls, the most remarkable spectral bands for this $\mathrm{PC}$ were those corresponding to the $\mathrm{CH}$ deformation vibration of the methyl $=\mathrm{C}\left(\mathrm{CH}_{3}\right)_{2}$ group. Bands that were pointed around 1,347 and $1,333 \mathrm{~cm}^{-1}$ were of almost equal intensity. There was also a band corresponding to $\mathrm{C}-\mathrm{C}$ skeletal vibrations of the $=\mathrm{C}\left(\mathrm{CH}_{3}\right)_{2}$ group.

With regard to the rest of bands observed on the spectra of different flavonoids, they could be associated with aromatic rings and hydroxyl functions, as in the case of the phenolic acids. 

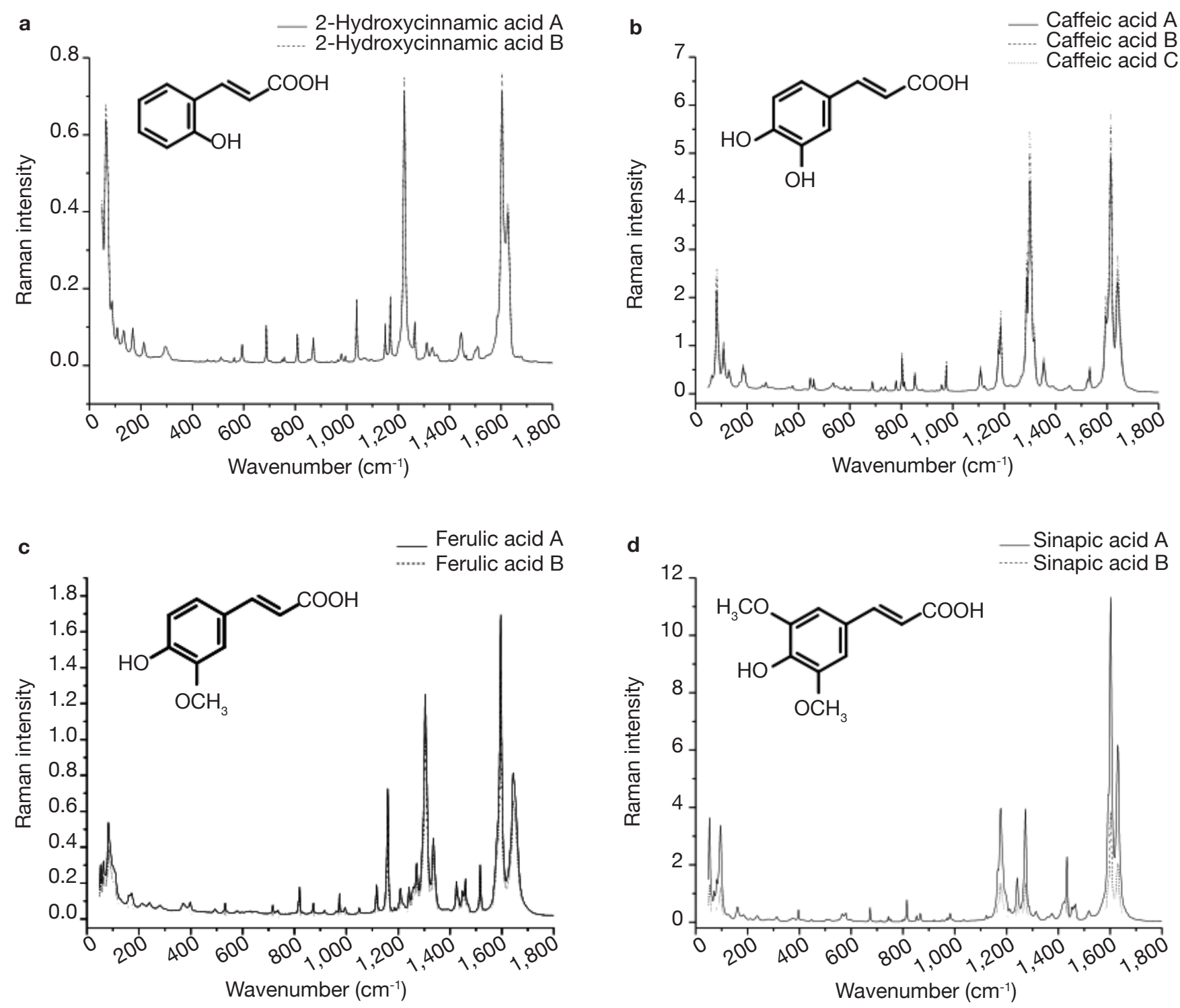

Figure 3. Raman spectra and chemical structures of 2-hydroxycinnamic (a), caffeic (b), ferulic (c) and sinapic (d) acids - Spectres Raman et structures chimiques des acides 2-hydroxycinnamique (a), caféique (b), férulique (c) et sinapique (d). 
Table 3. The most intense Raman scattering signals $\left(\mathrm{cm}^{-1}\right)$ of 2-hydroxycinnamic (2HC), cafeic, ferulic and sinapic acids - Les signaux Raman les plus intenses $\left(\mathrm{cm}^{-1}\right)$ des acides 2-hydroxycinnamique (2HC), caféique, férulique et sinapique.

\section{Hydroxycinnamic acids}

\begin{tabular}{llll} 
2HC & Cafeic & Ferulic & Sinapic \\
\hline $1,626_{v s}$ & $1,640-1,641_{v s}$ & $1,631_{v s}$ & $1,642_{v s}$ \\
$1,604_{v s}$ & $1,625_{w}$ & $1,602_{v s}$ & $1,595-1,596_{v s}$ \\
$1,585_{w}$ & $1,614-1,615_{v s}$ & $1,592_{s}$ & $1,516_{w}$ \\
$1,445_{w}$ & $1,602_{s}$ & $1,466_{v w}$ & $1,472_{v w}$ \\
$1,311_{v w}$ & $1,594_{s}$ & $1,459_{v w}$ & $1,460_{w}$ \\
$1,265_{w}$ & $1,533_{v w}$ & $1,433_{m}$ & $1,424-1,425_{w}$ \\
$1,224_{v s}$ & $1,354_{w}$ & $1,273_{s}$ & $1,336_{w}$ \\
$1,170_{m}$ & $1,317_{m}$ & $1,241_{w}$ & $1,310_{v s}$ \\
$1,150_{w}$ & $1,307_{v s}$ & $1,211_{v w}$ & $1,304_{v s}$ \\
$1,039_{m}$ & $1,299_{v s}$ & $1,201-1,202_{v w}$ & $1,271_{w}$ \\
$871_{v w}$ & $1,287_{v s}$ & $1,196_{v w}$ & $1,242_{v w}$ \\
$808_{w}$ & $1,186_{m}$ & $1,177_{s}$ & $1,209-1,210_{v w}$ \\
$687-688_{w}$ & $1,177_{w}$ & $1,164_{w}$ & $1,160_{v s}$ \\
\hline $594_{v w}$ & $975_{w}$ & $852_{v w}$ & $1,117_{w}$ \\
$168-169_{w}$ & $803_{w}$ & $815_{v w}$ & $974_{v w}$ \\
\hline $108_{w}$ & $184_{w}$ & $96_{m}$ & $820_{v w}$ \\
$88_{m}$ & $130_{v w}$ & $81_{w}$ & $533_{v w}$ \\
$71_{v s}$ & $109_{w}$ & $70-71_{v w}$ & $82_{s}$ \\
\hline $64_{v s}$ & $90_{m}$ & $63_{v w}$ & $64_{w}$ \\
$50_{v s}$ & $82_{v s}$ & $53-54_{m}$ & $52_{w}$ \\
\hline
\end{tabular}

Each compound from each brand was measured independently twice. These Raman scattering signals represent the average of these measures. The Raman scattering signals were codded with $v w$ (very weak: 5-10\%), $w$ (weak: 10-20\%), $m$ (medium: 20-30\%), s (strong: 30-40\%) and vs (very strong: > 40\%) in function of their relative Raman intensities concerning the highest Raman intensity - Chaque composé de chaque marque a été analysé deux fois indépendamment. Ces signaux représentent la moyenne de ces mesures. Les signaux Raman ont été codés avec vw (très faible : 5-10\%), w (faible : 10-20\%), m (moyen : 20-30\%), s (fort : 30-40 \%) et vs (très fort : $>40 \%)$ en fonction de leurs intensités Raman relatives à l'intensité Raman la plus élevée. 

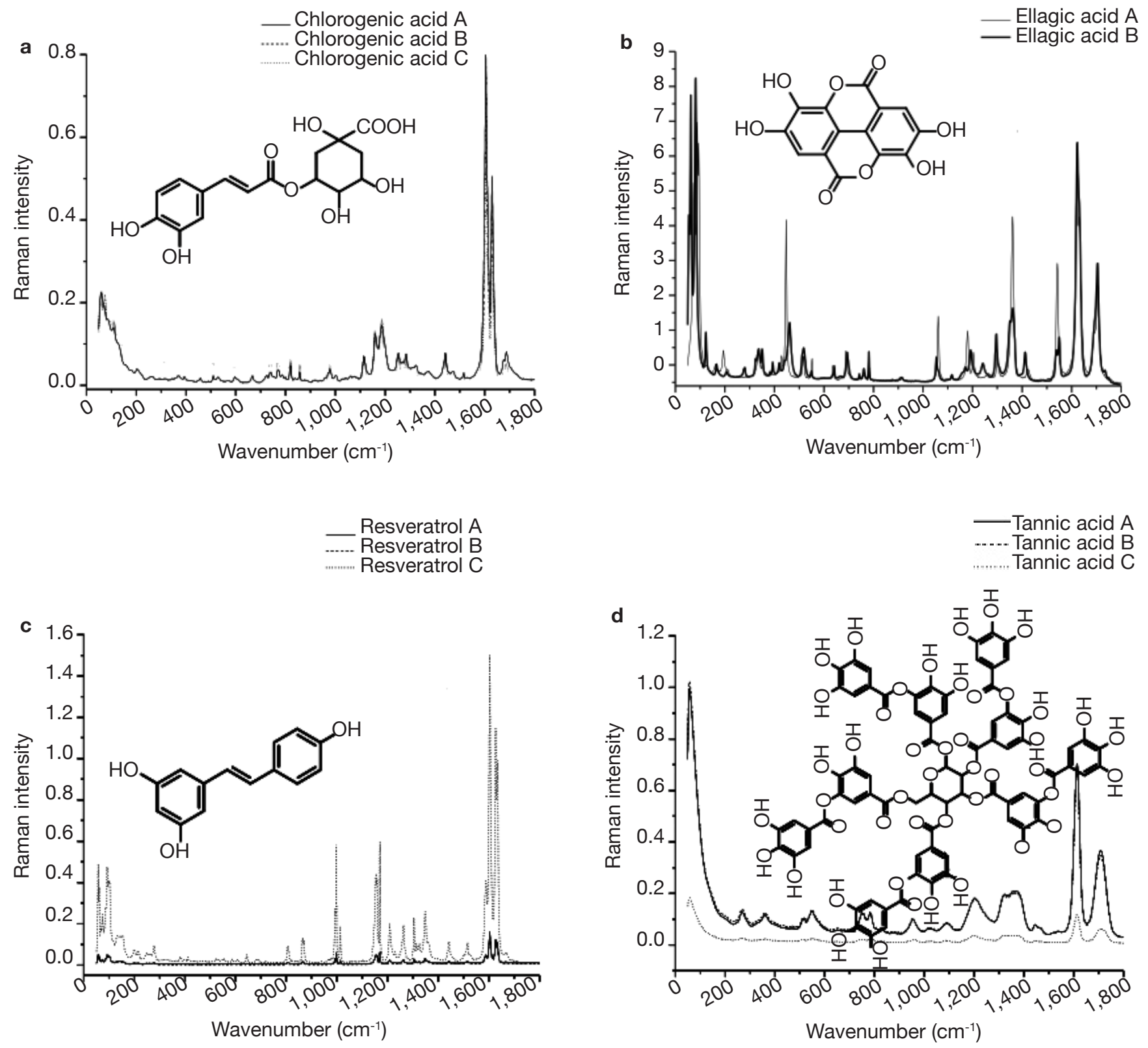

Figure 4. Raman spectra and chemical structures of chlorogenic (a) and ellagic (b) acids, resveratrol (c) and tannic acid (d) - Spectres Raman et structures chimiques des acides chlorogénique (a) et éllagique (b), du resvératrol (c) et de l'acide tannique $(\boldsymbol{d})$. 
Table 4. The most intense Raman scattering signals $\left(\mathrm{cm}^{-1}\right)$ of catechol, chlorogenic acid, resveratrol, and tannic acid - Les signaux Raman les plus intenses $\left(\mathrm{cm}^{-1}\right)$ du catéchol, d'acide chlorogénique, du resvératrol et d'acide tannique.

\section{Derivatives of hydroxybenzoic and hydrocinnamic acids}

Ellagic acid*

Chlorogenic acid

\begin{tabular}{ccllc}
\hline $1,707_{s}$ & $1,711_{w}$ & $1,687_{w}$ & $1,634-1,635_{v s}$ & $1,712_{s}$ \\
$1,633_{v s}$ & $1,705_{s}$ & $1,629_{v s}$ & $1,627_{v s}$ & $1,614_{v s}$ \\
$1,626_{v s}$ & $1,697_{m}$ & $1,612-1,613_{v s}$ & $1,604_{v s}$ & $1,445_{v w}$ \\
$1,620_{v s}$ & $1,640_{w}$ & $1,604-1,605_{v s}$ & $1,589_{m}$ & $1,327_{m}$ \\
$1,613_{m}$ & $1,633_{v s}$ & $1,515-1,516_{v w}$ & $1,348-1,349_{w}$ & $1,202_{w}$ \\
$1,543_{v s}$ & $1,627_{v s}$ & $1,460_{v w}$ & $1,304_{w}$ & $1,091_{v w}$ \\
$1,368_{m}$ & $1,622_{v s}$ & $1,443 \pm 1_{w}$ & $1,280_{w}$ & $960_{w}$ \\
$1,362_{v s}$ & $1,615_{m}$ & $1,285-1,286_{v w}$ & $1,169-1,170_{v s}$ & $788_{w}$ \\
$1,356_{s}$ & $1,370_{w}$ & $1,223_{w}$ & $1,158_{m}$ & $755_{w}$ \\
$1,180_{w}$ & $1,364_{w}$ & $1,189_{m}$ & $1,153-1,154_{m}$ & $547_{w}$ \\
$1,061_{m}$ & $1,355_{w}$ & $1,186-1,187_{m}$ & $997_{s}$ & $363_{w}$ \\
\hline $452_{w}$ & $1,349_{w}$ & $1,157 \pm 1_{w}$ & $993_{w}$ & $264_{w}$ \\
$448_{v s}$ & $462_{w}$ & $1,114 \pm 1_{w}$ & $103_{m}$ & $56_{v s}$ \\
\hline $443_{w}$ & $123_{w}$ & $856-857_{v w}$ & $98-99_{m}$ & \\
\hline $99_{v s}$ & $87_{s}$ & $766-767_{v w}$ & $92_{m}$ & \\
$95_{v s}$ & $82_{v s}$ & $76_{m}$ & $86_{w}$ & \\
\hline $91_{v s}$ & $75_{s}$ & $73_{m}$ & $73_{w}$ & \\
\hline $88_{v s}$ & $66_{v s}$ & $62_{m}$ & $66_{w}$ & \\
\hline $82_{v s}$ & $62_{v s}$ & $54_{m}$ & $51_{m}$ & \\
\hline $75_{v s}$ & $58_{v s}$ & $52_{m}$ & $56-57_{m}$ & \\
\hline
\end{tabular}

Each compound from each brand was measured independently twice. These Raman scattering signals represent the average of these measures. The Raman scattering signals were codded with $v w$ (very weak: 5-10\%), $w$ (weak: 10-20\%), $m$ (medium: 20-30\%), $s$ (strong: $30-40 \%$ ) and $v s$ (very strong: $>40 \%$ ) in function of their relative Raman intensities concerning the highest Raman intensity - Chaque composé de chaque marque a été analysé deux fois indépendamment. Ces signaux représentent la moyenne de ces mesures. Les signaux ont été codés avec vw (très faible : 5-10\%), w (faible : 10-20\%), m (moyen : 20-30\%), s (fort : 30-40\%) et vs (très fort : > 40 \%) en fonction de leurs intensités Raman relatives à l'intensité Raman la plus élevée; *: Raman scattering signals from ellagic acid brand A and B - Signaux Raman correspondant à l'acide éllagique A et B; **: Tannic acid presented just 14 peaks - L'acide tannique présente seulement 14 pics. 

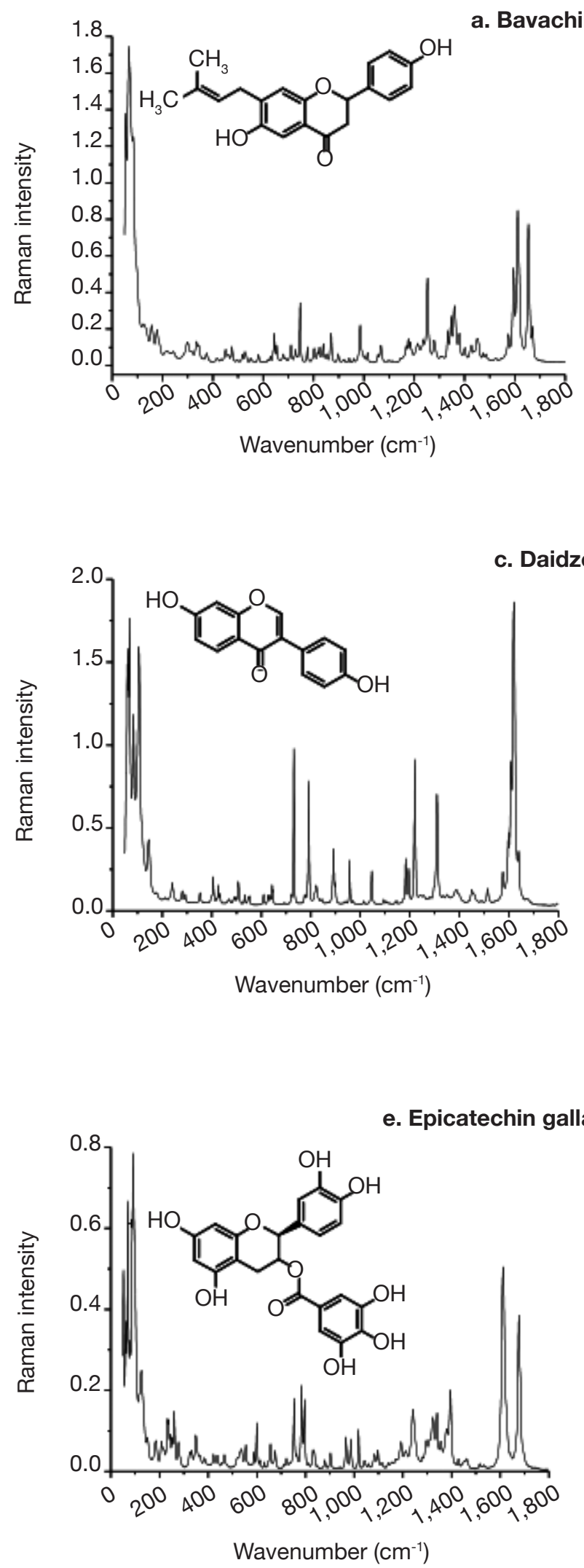
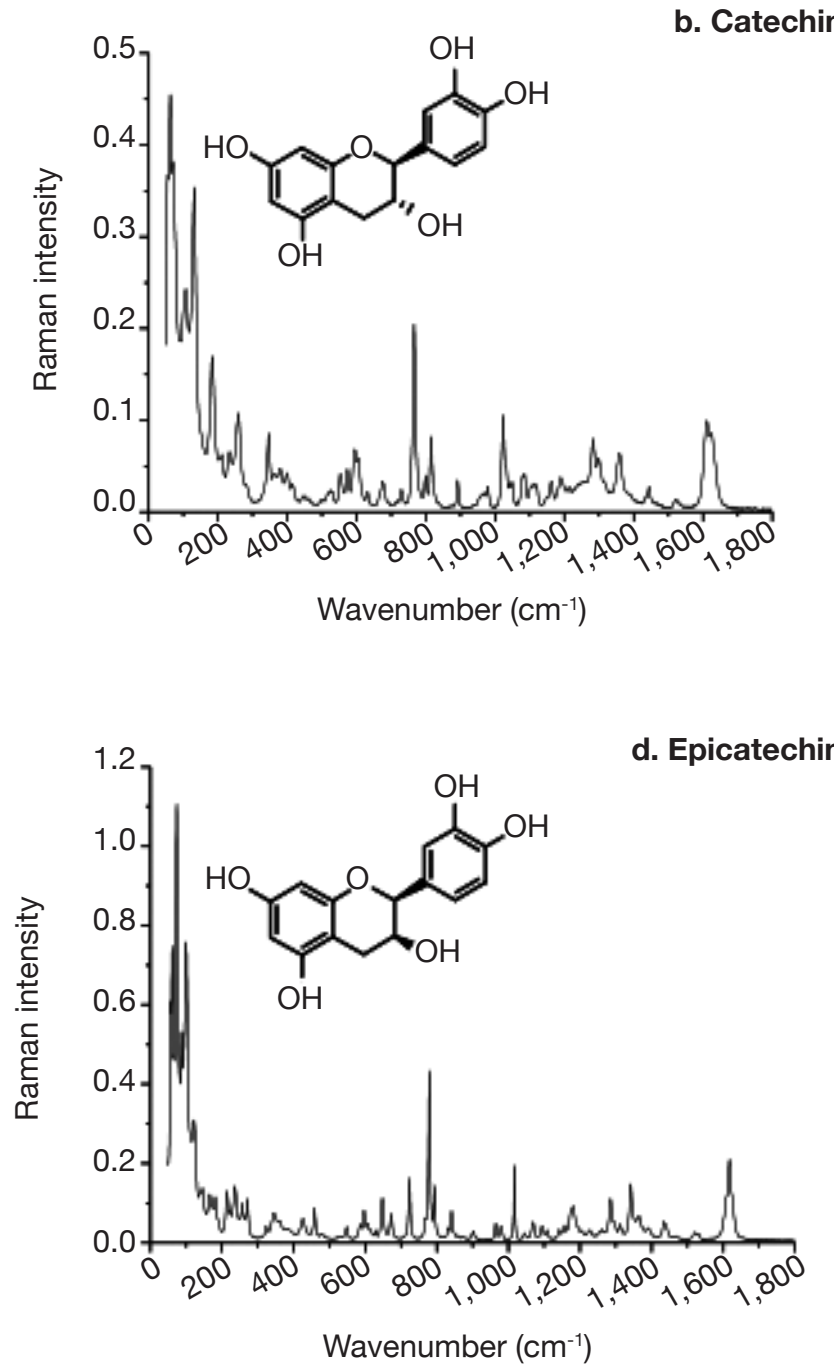

f. Epigallocatechin

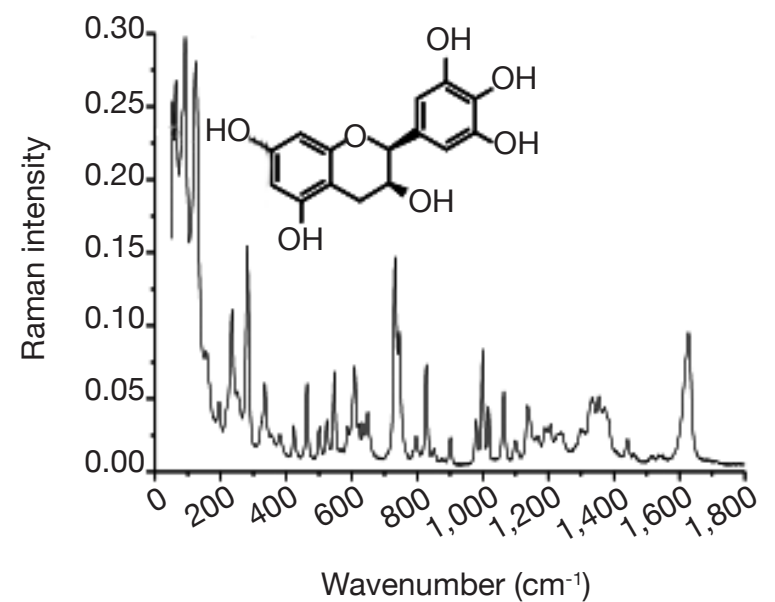

Figure 5a. Raman spectra and chemical structures of bavachinin (a), catechin (b), daidzein (c), epicatechin (d), epicatechin gallate (e), epigallocatechin (f) - Spectres Raman et structures chimiques de la bavachinine (a), catéchine (b), daidzéine (c), épicatechine $(\boldsymbol{d})$, gallate d'épicatéchine $(\boldsymbol{e})$ et épigallocatéchine $(\boldsymbol{f})$. 


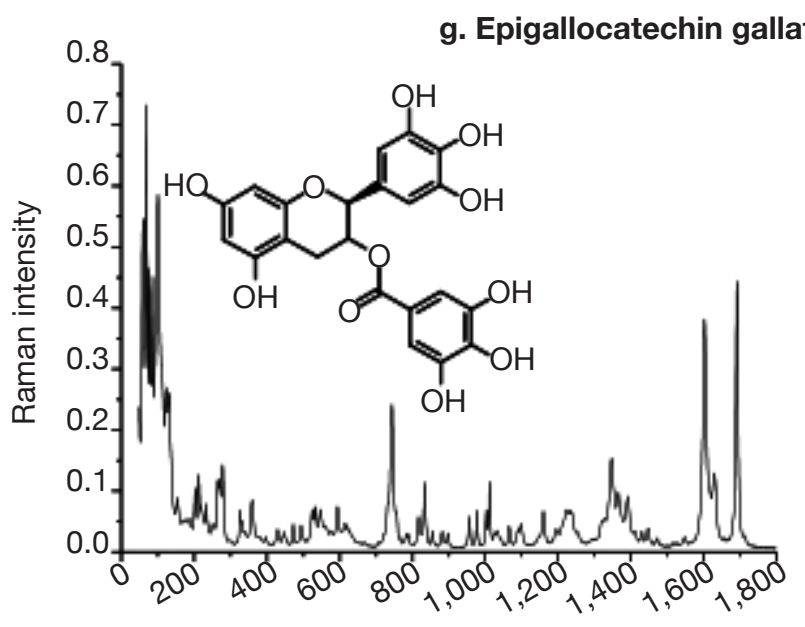

Wavenumber $\left(\mathrm{cm}^{-1}\right)$
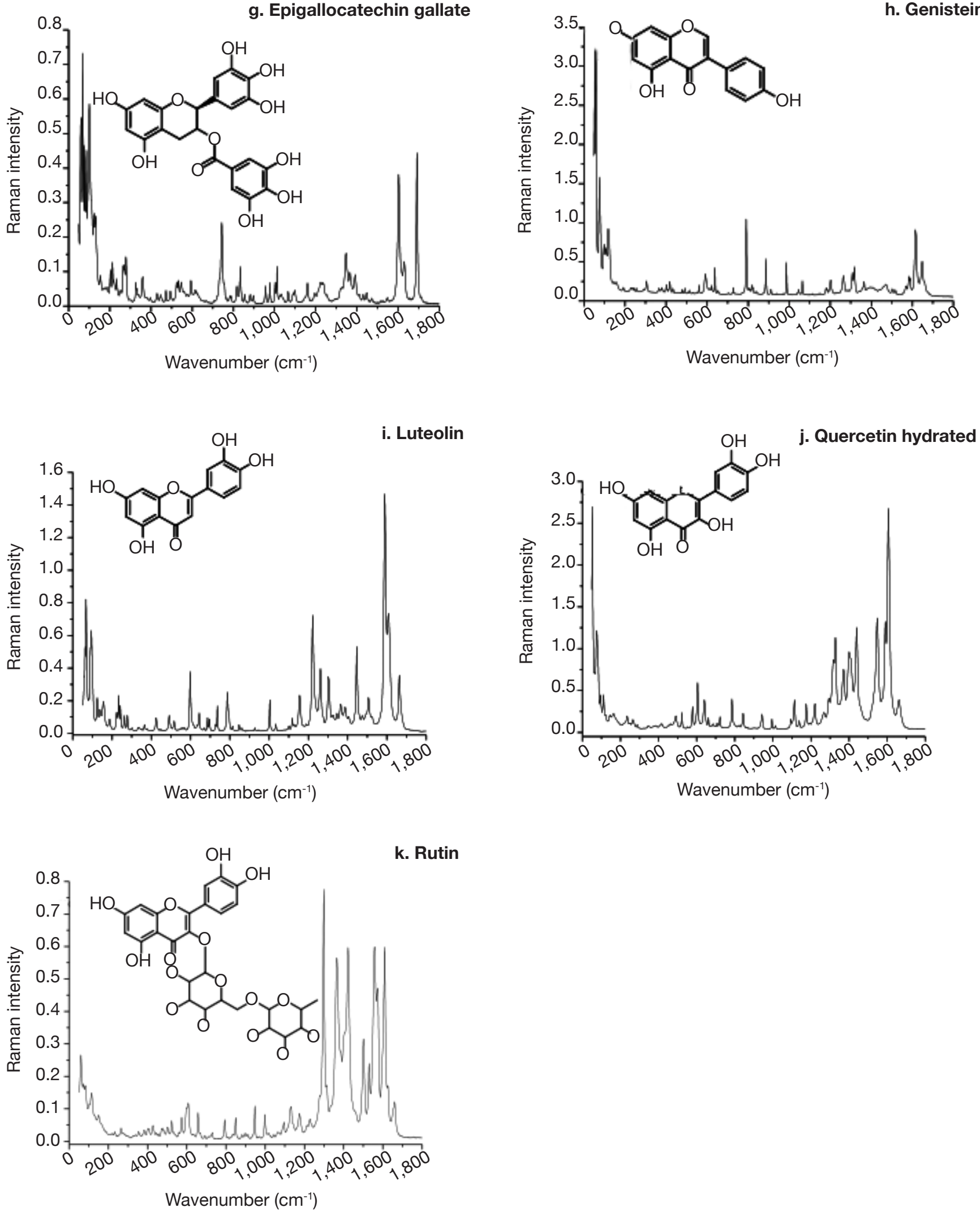

Figure 5b. Raman spectra and chemical structures of epigallocatechin gallate (g), genistein (h), luteolin (i), quercetin hydrated (j) and rutin (k) - Spectres Raman et structures chimiques de la bavachinine (a), catéchine (b), daidzéine (c), épicatechine $(\boldsymbol{d})$, gallate d'épicatéchine $(\mathbf{e})$, épigallocatéchine $(\boldsymbol{f})$, gallate de l'épigallocatéchine $(\boldsymbol{g})$, génistéine $(\boldsymbol{h})$, lutéoline $(\boldsymbol{i})$, quercétine hydratée $(\boldsymbol{j})$ et rutine $(\boldsymbol{k})$. 
Table 5. The most intense Raman scattering signals $\left(\mathrm{cm}^{-1}\right)$ of bavachinin (BVC), catechin (CAT), daidzein (DDZ), epicatechin (EPC), epicatechin gallate (EPCG), epigallocatechin (EPG), epigallocatechin gallate (EPGG), genistein (GNT), luteolin (LTL), quercetin dihydrated and rutin (RUT) - Les signaux Raman les plus intenses ( $\left.\mathrm{cm}^{-1}\right)$ de la bavachinine $(B V C)$, la catéchine (CAT), la daidzéine (DDZ), l'épicatéchine (EPC), le gallate d'épicatéchine (EPCG), l'épigallocatéchine (EPG), le gallate d'épigallocatéchine (EPGG), la génistéine (GNT), la lutéoline (LTL), la quercétine dihydratée et la rutine (RUT).

\section{Flavonoids}

\begin{tabular}{|c|c|c|c|c|c|c|c|c|c|c|}
\hline BVC & CAT & DDZ & EPC & EPCG & EPG & EPGG & GNT & LTL & QUER & RUT \\
\hline $1,670_{w}$ & $1,633_{w}$ & $1,640_{m}$ & $1,617_{w}$ & $1,683_{m}$ & $1,627_{s}$ & $1,692_{v s}$ & $1,658_{v w}$ & $1,663_{m}$ & $1,665_{w}$ & $1,660_{w}$ \\
\hline $1,653_{v s}$ & $1,283_{w}$ & $1,623_{v s}$ & $1,342_{w}$ & $1,676_{v s}$ & $1,000_{m}$ & $1,603_{v s}$ & $1,648_{w}$ & $1,589_{v s}$ & $1,606_{v s}$ & $1,610_{v}$ \\
\hline $1,618_{s}$ & $1,024_{m}$ & $1,618_{v s}$ & $1,286_{w}$ & $1,614_{v s}$ & $998_{m}$ & $1,012_{w}$ & $1,619_{m}$ & $1,446_{s}$ & $1,590_{v s}$ & $1,576_{v s}$ \\
\hline $1,611_{v s}$ & $816_{w}$ & $1,608_{v s}$ & $1,017_{w}$ & $1,610_{v s}$ & $745_{s}$ & $1,003_{v w}$ & $1,615_{m}$ & $1,301_{m}$ & $1,548_{v s}$ & $1,574_{v s}$ \\
\hline $1,594_{s}$ & $814_{w}$ & $1,599_{m}$ & $794_{w}$ & $1,609_{v s}$ & $735_{v s}$ & $834_{w}$ & $1,318_{w}$ & $1,223_{v s}$ & $1,441_{v s}$ & $1,560_{v s}$ \\
\hline $1,347_{w}$ & $766_{v s}$ & $1,310_{s}$ & $779_{s}$ & $1,396_{m}$ & $733_{v s}$ & $744_{s}$ & $1,308_{w}$ & $1,004_{w}$ & $1,398_{s}$ & $1,558_{v}$ \\
\hline $1,333_{w}$ & $346_{w}$ & $1,220_{v s}$ & $724_{w}$ & $1,341_{w}$ & $731_{v s}$ & $740_{m}$ & $1,064_{v w}$ & $787_{w}$ & $1,328_{v s}$ & $1,556_{v s}$ \\
\hline $1,253_{m}$ & $262_{m}$ & $1,196_{w}$ & $648_{w}$ & $796_{m}$ & $729_{s}$ & $279_{w}$ & $987_{w}$ & $737_{w}$ & $1,175_{w}$ & $1,553_{v s}$ \\
\hline $1,177_{v w}$ & $134_{v s}$ & $892_{m}$ & $270_{v w}$ & $784_{m}$ & $282_{v s}$ & $265_{w}$ & $887_{w}$ & $686_{v w}$ & $1,114_{w}$ & $1,530_{s}$ \\
\hline $985_{w}$ & $131_{v s}$ & $791_{v s}$ & $256_{v w}$ & $753_{m}$ & $281_{v s}$ & $233_{w}$ & $791_{s}$ & $597_{m}$ & $995_{v w}$ & $1,501_{v s}$ \\
\hline $839_{v w}$ & $186_{s}$ & $775_{v w}$ & $235_{w}$ & $260_{w}$ & $235_{s}$ & $213_{w}$ & $728_{v w}$ & $263_{v w}$ & $785_{w}$ & $1,422_{v s}$ \\
\hline $823_{v w}$ & $184_{s}$ & $731_{v s}$ & $214_{w}$ & $238_{w}$ & $234_{s}$ & $203_{w}$ & $638_{w}$ & $243_{w}$ & $722_{v w}$ & $1,365_{v s}$ \\
\hline $776_{v w}$ & $183_{s}$ & $118_{m}$ & $181_{w}$ & $125_{s}$ & $124_{v s}$ & $131_{s}$ & $561_{v w}$ & $234_{w}$ & $662_{v w}$ & $1,299_{v s}$ \\
\hline $747_{w}$ & $182_{s}$ & $106_{v s}$ & $121_{m}$ & $100_{v s}$ & $119_{v s}$ & $124_{s}$ & $491_{v w}$ & $124_{w}$ & $605_{m}$ & $998_{w}$ \\
\hline $728_{v w}$ & $92_{v s}$ & $84_{v s}$ & $100_{v s}$ & $92_{v s}$ & $92_{v s}$ & $100_{v s}$ & $419_{v w}$ & $95_{v s}$ & $579_{w}$ & $947_{w}$ \\
\hline $710_{v w}$ & $76_{v s}$ & $74_{v s}$ & $88_{v s}$ & $86_{v s}$ & $84_{v s}$ & $86_{v s}$ & $123_{m}$ & $89{ }_{s}$ & $522_{v w}$ & $849_{v}$ \\
\hline $653_{v w}$ & $70_{v s}$ & $68_{v s}$ & $73_{v s}$ & $78_{v s}$ & $76_{v s}$ & $77_{v s}$ & $117_{m}$ & $72_{s}$ & $111_{w}$ & $793_{v n}$ \\
\hline $85_{v s}$ & $63_{v s}$ & $62_{v s}$ & $65_{v s}$ & $69_{v s}$ & $64_{v s}$ & $68_{v s}$ & $80_{s}$ & $67_{v s}$ & $83_{s}$ & $657_{w}$ \\
\hline $66_{v s}$ & $60_{v s}$ & $58_{v s}$ & $60_{v s}$ & $61_{v s}$ & $61_{v s}$ & $60_{v s}$ & $76_{v s}$ & 62 s & $76_{v s}$ & $523_{v n}$ \\
\hline \multirow[t]{3}{*}{$53_{v s}$} & $54_{v s}$ & $53_{v s}$ & $56_{v s}$ & $52_{v s}$ & $53_{v s}$ & $58_{v s}$ & $58_{v s}$ & $57_{m}$ & $72_{v s}$ & $84_{m}$ \\
\hline & & & & & & & $52_{v s}$ & & $52_{v s}$ & $60 s$ \\
\hline & & & & & & & $50_{v s}$ & & & \\
\hline
\end{tabular}

Each compound was measured independently twice. These Raman scattering signals represent the average of these measures. The wavenumbers were codded with $v w$ (very weak: 5-10\%), $w$ (weak: 10-20\%), $m$ (medium: 20-30\%), s (strong: 30-40\%) and vs (very strong: > 40\%) in function of their relative Raman intensities concerning the highest Raman intensity - Chaque composé a été analysé deux fois indépendamment. Ces signaux de diffusion Raman représentent la moyenne de ces mesures. Les nombres d'ondes ont été codés avec vw (très faible : 5-10 \%), w (faible : 10-20\%), m (moyen : 20-30\%), s (fort : 30-40\%) et vs (très fort : > $40 \%$ ) en fonction de leurs intensités Raman relatives à l'intensité Raman la plus élevée.

\section{DIFFERENTIATION OF PHENOLIC COMPOUNDS WITHIN AND BETWEEN GROUPS}

Principal component analysis (PCA) of SNV pre-treated Raman scattering signals was used to differentiate PCs within each class. For the hydroxybenzoic acids, six classes were formed and the most important Raman scattering signals that differentiated these PCs were: $1,697,1,612,1,600,1,594,1,592$ and $1,198 \mathrm{~cm}^{-1}$, as well as the region between 140 and $50 \mathrm{~cm}^{-1}$. For the hydroxycinnamic acids, all the PCs were well differentiated and four groups were formed. The most important Raman scattering signals responsible for this differentiation were: $1,642,1,630,1,614$, $1,602,1,596,1,305-1,270,1,224,1,178,1,160$ and $64 \mathrm{~cm}^{-1}$. The derivatives of hydroxybenzoic and hydroxycinnamic acids (chlorogenic and ellagic acids, resveratrol and tannic acid) were very well separated. The most important Raman scattering signals responsible for this differentiation were: 1,635 , $1,631,1,628,1,626,1,611,1,606,1,604,1,348,1,170$, 
$997,447,88,61$ and $57 \mathrm{~cm}^{-1}$. In the flavonoid family, three groups were clearly separated. In the first there were two flavonols, quercetin and rutin, and a flavone, luteolin; these PCs are very close chemically. In the second group there were two isoflavones, dadzein and genistein, and a prenylflavone, bavachinin. The third group consisted entirely of flavanols: catechin, epicatechin, epicatechin gallate, epigallocatechin and epigallocatechin gallate. The most important Raman scattering signals responsible for this differentiation were: $1,616,1,608,1,557,1,423,1,298,1,222,791$ and below $130 \mathrm{~cm}^{-1}$. Differentiation between classes was also done. Here, the Fisher ratio was used to select the 20 most important Raman scattering signals that allowed hydroxybenzoic (HBA) and hydroxycinnamic acids (HCA) to be differentiated, as well as their derivatives (DEV) and flavonoids (FLAV). The differentiation combinations were: HBA versus $\mathrm{HCA}$; HBA versus DEV; HBA versus FLAV; HCA versus
DEV; HCA versus FLAV; and DEV versus FLAV. Table 6 shows the Raman scattering signals that allowed these combinations to be differentiated. The $1,600-1,699 \mathrm{~cm}^{-1}$ and $50-199 \mathrm{~cm}^{-1}$ spectral ranges presented 19 and 25 peaks, respectively, that were used to discriminate the PCs. Peaks around 1,600-1,699 $\mathrm{cm}^{-1}$ were due to stretching vibrations of the $\mathrm{C}=\mathrm{C}$ and $\mathrm{C}=\mathrm{O}$ groups and those below $200 \mathrm{~cm}^{-1}$ were due to skeletal vibration. Another important spectral range was from 1,300 to $1,399 \mathrm{~cm}^{-1}$, which had 10 Raman scattering signals. These signals were due to stretching of the $\mathrm{CH}$ groups and the $\mathrm{OH}$ bending vibrations.

\section{Acknowledgements}

The authors are grateful to the Académie de Recherche et d'Enseignement supérieur (ARES) (Belgium), Conselho Nacional de Desenvolvimento Científico e Tecnológico

Table 6. Raman scattering signals $\left(\mathrm{cm}^{-1}\right)$ used to discriminate groups of phenolic compounds - Signaux Raman $\left(\mathrm{cm}^{-1}\right)$ utilisés pour discriminer les groupes de composés phénoliques.

\begin{tabular}{|clllllllll}
\hline $\begin{array}{l}\text { HBA } v s \\
\text { HCA }\end{array}$ & $\begin{array}{l}\text { HBA } v s \\
\text { DEV }\end{array}$ & $\begin{array}{l}\text { HBA } v s \\
\text { FLAV }\end{array}$ & $\begin{array}{l}\text { HCA } v s \\
\text { DEV }\end{array}$ & $\begin{array}{l}\text { HCA } v s \\
\text { FLAV }\end{array}$ & $\begin{array}{l}\text { DEV } v s \\
\text { FLAV }\end{array}$ & $\begin{array}{l}\text { HBA } v s \\
\text { HCA, DEV } \\
\text { FLAV }\end{array}$ & $\begin{array}{l}\text { HCA } v s \\
\text { HBA, DEV, } \\
\text { FLAV }\end{array}$ & $\begin{array}{l}\text { DEV } v s \\
\text { HBA, HCA } \\
\text { and FLAV }\end{array}$ & $\begin{array}{l}\text { FLAV HBA, } \\
\text { HCA, DEV }\end{array}$ \\
\hline 1,697 & 1,706 & 1,697 & 1,705 & 1,692 & 1,706 & 1,697 & 1,697 & 1,705 & 1,697 \\
\hline 1,642 & 1,697 & 1,676 & 1,642 & 1,642 & 1,634 & 1,628 & 1,642 & 1,692 & 1,628 \\
1,630 & 1,634 & 1,619 & 1,634 & 1,630 & 1,628 & 1,615 & 1,631 & 1,653 & 1,614 \\
\hline 1,614 & 1,628 & 1,609 & 1,627 & 1,615 & 1,604 & 1,604 & 1,615 & 1,628 & 1,603 \\
1,603 & 1,604 & 1,554 & 1,615 & 1,602 & 1,589 & 1,598 & 1,602 & 1,604 & 1,556 \\
\hline 1,595 & 1,598 & 1,421 & 1,605 & 1,366 & 1,557 & 1,362 & 1,595 & 1,594 & 1,398 \\
1,300 & 1,361 & 1,365 & 1,600 & 1,300 & 1,423 & 1,300 & 1,300 & 1,362 & 1,364 \\
\hline 1,224 & 1,315 & 1,316 & 1,595 & 1,287 & 1,398 & 1,289 & 1,287 & 1,299 & 1,304 \\
\hline 1,198 & 1,289 & 1,288 & 1,300 & 1,273 & 1,299 & 1,224 & 1,273 & 1,288 & 1,287 \\
\hline 1,186 & 1,265 & 1,221 & 1,287 & 1,224 & 1,221 & 1,170 & 1,224 & 1,224 & 1,221 \\
\hline 1,178 & 1,170 & 1,198 & 1,273 & 1,186 & 1,170 & 1,158 & 1,186 & 1,170 & 1,198 \\
\hline 1,160 & 997 & 802 & 1,223 & 1,178 & 1,155 & 997 & 1,160 & 1,158 & 1,179 \\
\hline 749 & 802 & 779 & 1,178 & 1,160 & 1,043 & 802 & 776 & 997 & 1,158 \\
\hline 139 & 776 & 731 & 1,154 & 791 & 997 & 750 & 123 & 776 & 791 \\
\hline 122 & 139 & 233 & 997 & 731 & 776 & 741 & 111 & 123 & 731 \\
\hline 111 & 122 & 140 & 776 & 124 & 125 & 139 & 106 & 106 & 124 \\
\hline 100 & 106 & 126 & 117 & 101 & 101 & 122 & 100 & 100 & 100 \\
\hline 83 & 83 & 111 & 94 & 74 & 81 & 106 & 83 & 83 & 83 \\
\hline 68 & 76 & 83 & 80 & 68 & 69 & 100 & 76 & 69 & 69 \\
\hline 57 & 55 & 69 & 57 & 58 & 55 & 52 & 57 & 57 & 59 \\
\hline
\end{tabular}

HBA: hydroxybenzoic acids - acides hydroxybenzöques; HCA: hydroxycinnamic acids - acides hydroxycinnamiques; DEV: derivatives of hydroxybenzoic and hydroxycinnamic acids - dérivés d'acides hydroxybenzoïques et hydroxycinnamiques; FLAV: flavonoids - flavonoïdes; These Raman scattering signals were selected using the Fisher test at $\alpha=0.05-$ Ces signaux Raman ont été sélectionnés en utilisant le test de Fisher à $\alpha=0,05$. 
(CNPq) and Fundação Amazônia de Amparo a Estudos e Pesquisas do Pará (FAPESPA) (Brazil) for the financial support received to carry out this work. The authors would also like to thank very much Quentin Arnould and Sandrine Mauro from Walloon Agricultural Research Centre (CRA-W) for their technical assistance.

\section{Bibliography}

Baeten V., Dardenne P. \& Aparicio R., 2001. Interpretation of Fourier transform Raman spectra of the unsaponifiable matter in a selection of edible oils. J.Agric.Food Chem., 49, 5098-5107.

Baeten V. et al., 2015. Vibrational spectroscopy methods for the rapid control of agro-food products. In: Nollet L.M.L. \& Toldra F., eds. Handbook of food analysis. $3^{\text {rd }}$ ed. Vol. 2. Boca Raton, FL, USA: CRC Press, 591-614.

Baranska M. et al., 2004. Identification of secondary metabolites in medicinal and spice plants by NIR-FTRaman microspectroscopic mapping. Analyst, 129, 926930.

Baranska M., Schulz H., Joubert E. \& Manley M., 2006. In situ flavonoid analysis by FT-Raman spectroscopy: identification, distribution, and quantification of aspalathin in green rooibos (Aspalathus linearis). Anal. Chem., 78, 7716-7721.

Billes F., Mohammed-Ziegler I., Mikosch H. \& Tyihák E., 2007. Vibrational spectroscopy of resveratrol. Spectrochim. Acta Part A, 68, 669-679.

Calheiros R. et al., 2008. Antioxidant phenolic esters with potential anticancer activity: a Raman spectroscopy study. J. Raman Spectrosc., 39, 95-107.

Corredor C. et al., 2009. Raman and surface-enhanced Raman spectra of chrysin, apigenin, and luteolin. Vib. Spectrosc., 49, 190-195.

Eravuchira P.J. et al., 2012. Raman spectroscopic characterization of different regioisomers of monoacyl and diacyl chlorogenic acid. Vib. Spectrosc., 61, 10-16.

Fiuza S.M. et al., 2004. Phenolic acid derivatives with potential anticancer properties - A structure-activity relationship study. Part 1: methyl, propyl and octyl esters of caffeic and gallic acids. Bioorg. Med. Chem., 12, 3581-3589.

Ignat I., Volf I. \& Popa V.I., 2011. A critical review of methods for characterisation of polyphenolic compounds in fruits and vegetables. Food Chem., 126, 1821-1835.

ISO 5725, 1994. Accuracy (trueness and precision) of measurement methods and result - Part 1: general principles and definitions. Roma: FAO.
Machado N.F.L., Batista de Carvalho L.A.E., Otero J.C. \& Marques M.P.M., 2013. A conformational study of hydroxyflavones by vibrational spectroscopy coupled to DFT calculations. Spectrochim. Acta Mol. Biomol. Spectrosc., 109, 116-124.

Mishra S. et al., 2013. Vibrational spectroscopy and density functional theory analysis of 3-O-caffeoylquinic acid. Spectrochim. Acta Mol. Biomol. Spectrosc., 104, 358367.

Numata Y. \& Tanaka H., 2011. Quantitative analysis of quercetin using Raman spectroscopy. Food Chem., 126, 751-755.

Paiva-Martins F., Rodrigues V., Calheiros R. \& Marques M.P.M., 2010. Characterization of antioxidant olive oil biophenols by spectroscopic methods. J. Sci. Food Agric., 91, 309-314.

Robards K. et al., 1999. Phenolic compounds and their role in oxidative processes in fruits. Food Chem., 66, 401436.

Schrader B., Klump H.H., Schenzel K. \& Schulz H., 1999. Non-destructive NIR FT Raman analysis of plants. J. Mol. Struct., 509, 201-212.

Schulz H. et al., 2005. Characterisation of essential oil plants from Turkey by IR and Raman spectroscopy. Vib. Spectrosc., 39, 249-256.

Socrates G., 1997. Infrared characteristic group frequencies. Tables and Charts. $2^{\text {nd }}$ ed. John Wiley \& Sons.

Świsłocka R., Kowczyk-Sadowy M., Kalinowska M. \& Lewandowski W., 2012. Spectroscopic (FT-IR, FTRaman, $1 \mathrm{H}$ and 13C NMR) and theoretical studies of p-coumaric acid and alkali metal p-coumarates. Spectroscopy, 27, 35-48.

Świsłocka R., Regulska E., Samsonowicz M. \& Lewandowski W., 2013. Experimental and theoretical study on benzoic acid derivatives. J. Raman Spectrosc., 1044, 181-187.

Teslova T. et al., 2007. Raman and surface-enhanced Raman spectra of flavone and several hydroxy derivatives. J. Raman Spectrosc., 38, 802-818.

Volf I., Ignat I., Neamtu M. \& Popa V.I., 2014. Thermal stability, antioxidant activity, and photo-oxidation of natural polyphenols. Chem. Pap., 68(1), 121-129.

Zuk M. et al., 2011. IR and Raman studies of oil and seedcake extracts from natural and genetically modified flax seeds. Spectrochim. Acta Part A., 78(3), 1080-1089.

(24 ref.) 